\title{
Small-Scale Flat Plate Collectors for Solar Thermal Scavenging in Low Conductivity Environments
}

\author{
Emmanuel Ogbonnaya and Leland Weiss \\ College of Engineering and Science, Louisiana Tech University, P.O. Box 10348, Ruston, LA 71272, USA \\ Correspondence should be addressed to Leland Weiss; lweiss@latech.edu
}

Received 10 February 2017; Revised 18 May 2017; Accepted 29 May 2017; Published 3 August 2017

Academic Editor: Michel Feidt

Copyright ( 2017 Emmanuel Ogbonnaya and Leland Weiss. This is an open access article distributed under the Creative Commons Attribution License, which permits unrestricted use, distribution, and reproduction in any medium, provided the original work is properly cited.

\begin{abstract}
There is great opportunity to develop power supplies for autonomous application on the small scale. For example, remote environmental sensors may be powered through the harvesting of ambient thermal energy and heating of a thermoelectric generator. This work investigates a small-scale (centimeters) solar thermal collector designed for this application. The absorber is coated with a unique selective coating and then studied in a low pressure environment to increase performance. A numerical model that is used to predict the performance of the collector plate is developed. This is validated based on benchtop testing of a fabricated collector plate in a low-pressure enclosure. Model results indicate that simulated solar input of about $800 \mathrm{~W} / \mathrm{m}^{2}$ results in a collector plate temperature of $298 \mathrm{~K}$ in ambient conditions and up to $388 \mathrm{~K}$ in vacuum. The model also predicts the various losses in $\mathrm{W} / \mathrm{m}^{2} \mathrm{~K}$ from the plate to the surroundings. Plate temperature is validated through the experimental work showing that the model is useful to the future design of these small-scale solar thermal energy collectors.
\end{abstract}

\section{Introduction}

There is both need and opportunity to develop small-scale autonomous power supplies that can operate sensors or other devices that require power input for continuous operation. Examples include remote environmental sensors that can monitor water, air, or other critical conditions. Solar thermal power generation for small-scale devices is one means to achieve a low-cost solution that may be deployed to these remote locations.

In these solar thermal systems, maximizing absorption while limiting losses due to convection and radiation is criti$\mathrm{cal}$ in achieving high temperature values. Typically, these systems use a formal collector plate or absorber that is heated by the incoming solar energy. A selective absorber coating is used to enhance absorption and limit reradiation losses. In addition to this plate coating, additional steps that improve collector operation can include transparent thermal insulation. This reduces convection and conduction losses from the heated collector plate, while still allowing incoming solar energy to heat the absorber plate surface. This work examines thermal insulation in solar thermal applications.
In general, there are many types of insulation available on the market. The basic consideration in selecting any particular insulation material is to reduce the flow of heat from one point to the other. Specific parameters such as thermal conductivity, operating temperature, combustibility, chemical stability, mechanical strength and durability, and cost are also considered in the material selection process.

The thermal conductivity of traditional thermal insulation materials like mineral wool, expanded polystyrene (EPS), and extruded polystyrene (XPS) is in the range of $0.033 \mathrm{~W} / \mathrm{mK}$ to $0.040 \mathrm{~W} / \mathrm{mK}$, while polyurethane (PUR) has thermal conductivity ranging from $0.020 \mathrm{~W} / \mathrm{mK}$ to $0.030 \mathrm{~W} / \mathrm{mK}$ [1-3]. To achieve very low thermal transmittance, $U$-value (rate of heat transfer, in watts, across one square meter area divided by the temperature gradient across the surface), high insulation thickness in the range of $40 \mathrm{~cm}$ to $50 \mathrm{~cm}$ is required [3]. Hence, space and weight constraints limit the application of these materials. More so, these materials are not transparent to solar radiation and therefore do not readily find application in solar thermal collectors.

Another growing insulation material is aerogel. One advantage of this material is its light weight (about $90 \%$ 
porosity). Further, silica aerogel granulate nanostructured material has been reported to have high solar transmittance and low thermal conductivity and is commercially available with thermal conductivity as low as $0.012 \mathrm{~W} / \mathrm{mK}$ and thickness in the mm range [4-6]. For a required thermal performance, aerogel exhibits a reduced thickness compared to traditional insulation. Hence, silica aerogel has a promising potential in solar thermal applications. However, the cost of aerogel insulation at this time is still relatively high.

Other techniques being actively explored for flat plate solar thermal applications include vacuum insulation panels [7] and gas-filled panels [8]. In vacuum insulation, the volume between the absorber plate and the cover glass is evacuated thereby limiting convection and conduction losses. The concept of vacuum insulation was invented in 1892 by Sir James Dewar. The Dewar flask consisted of two flasks, one placed within the other and joined at the neck, with the gap between the two flasks partially evacuated of air. Conduction and convection heat transfer is eliminated by the nearvacuum environment. In reality, a perfect vacuum is never achieved. However, low pressure environments positively influence gas conductivity. This technique is also used in glass window panels.

In the absence of sufficient vacuum, there is the possibility to fill the volume above a solar collector plate with a low thermal conductivity gas such as argon (Ar), krypton $(\mathrm{Kr})$, and xenon $(\mathrm{Xe})$. This way the gas-filled panel enhances insulation qualities as gas conductivity is lowered. In both vacuum insulation and gas-filled panel, hermetic sealing is critical. For micro scale applications, there are many established vacuum packaging/encapsulation techniques with airtight seals [9]. This makes the vacuum technique promising in the field of small-scale solar thermal collectors.

This work investigates vacuum insulation technology with a small-scale flat plate solar thermal collector to reduce energy losses from the plate to a minimum. Specifically the effect of low pressure on the thermal performance of the collector plate is modeled and then validated through experimental effort. In final form, the assembled solar collector will capture incoming solar energy and provide power for autonomous sensors or other systems that may be sustainably operated. Figure 1 shows the final assembled system that includes the evacuated space that is the primary focus of this paper. The collector assembly also includes a "selective" thermal collector plate that allows capture of solar energy while limiting losses from the heated plate in the infrared region.

\section{Materials and Methods}

This section describes numerical and experimental investigations conducted to thermally characterize the performance of solar collector plates in low thermal conductive environments. First, the numerical methods that provide insight and expectations for the operation of these plates in a low pressure environment are presented. Second, the fabrication of the plates is reviewed.

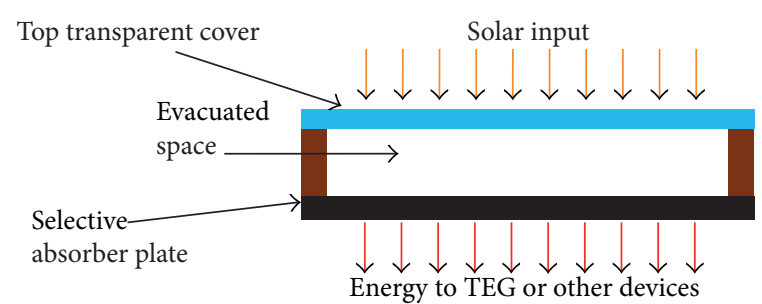

Figure 1: Solar collector system for environmental energy scavenging.

2.1. Numerical Methods. This section reviews the approach and methods employed to produce a numerical model of the small-scale STC (solar thermal collector) within a low conductivity space. This begins with an overview of temperature in evacuated spaces and proceeds to describe the equations required to model an overall heat transfer coefficient associated with these environments. These equations formed the foundation for numerical results in this present work.

2.1.1. Temperature Variation in Evacuated Spaces. In an enclosed volume, such as flat plate collectors, the pressure (density) of the gas between the plate and cover glass (top transparent cover, Figure 1) may be sufficiently lowered so that free-convection flow velocities are very small. This way, the only form of heat transfer between the gas molecules is by conduction. The kinetic theory of gases describes a gas as molecules in continuous random motion, colliding with one another and with the walls of the container. The collisions result in exchange of energy and momentum. That is, when a molecule moves from a high-temperature region to a lower-temperature region, it carries with it kinetic energy to the lower-temperature region. The kinetic energy is exchanged with the lower energy molecules through collision. The average distance a molecule travels between collisions is described by the mean free path $\lambda$, and can be calculated using [10]

$$
\lambda=\frac{1}{n \sqrt{2 \pi d^{2}}},
$$

where $n$ is the gas number density and $d$ is the average diameter (in meters) of the gas molecules. From kinetic theory of gases, the pressure (in Pascals) and number density of a gas molecule are related as shown in [10]

$$
P=n k T,
$$

where $K$ is the Boltzmann constant $\left(1.38 \times 10^{-23} \mathrm{JK}^{-1}\right)$ and $T$ is the gas temperature in Kelvin (K). Applying (2) into (1), the mean free path can be obtained by

$$
\lambda=\frac{K T}{P \sqrt{2 \pi d^{2}}} .
$$

The average diameter, $d$, of air $\left(3.16 \times 10^{-10} \mathrm{~m}\right)$ is obtained by a weighted average $(79: 21)$ of the molecular diameters of nitrogen $\left(3.2 \times 10^{-10} \mathrm{~m}\right)$ and oxygen $\left(3.0 \times 10^{-10} \mathrm{~m}\right)$. An approximate mean free path equation for the air molecules is therefore given by (4) and (5). When 
TABLE 1: Flow regimes versus Knudsen number.

\begin{tabular}{lcc}
\hline Knudsen number & Pressure (Torr) & Flow regime \\
\hline Kn $<0.001$ & $P>9$ & Continuum flow \\
$0.001<\mathrm{Kn}<0.1$ & $0.09<P<9$ & Slip flow \\
$0.1<\mathrm{Kn}<10$ & $0.0009<P<0.09$ & Transitional flow \\
$10<\mathrm{Kn}$ & $P<0.0009$ & Molecular flow \\
\hline
\end{tabular}

gases other than air are utilized, the diameter of the gas molecule is used accordingly to determine the mean free path. In all cases, however, the mean free path increases (and hence energy transfer is reduced) as the pressure is lowered, assuming steady-state temperature conditions.

$$
\begin{aligned}
& \lambda(m)=3.11 \times 10^{-5} \frac{T}{P_{\mathrm{Pa}}}, \\
& \lambda(m)=2.33 \times 10^{-7} \frac{T}{P_{\mathrm{Torr}}} .
\end{aligned}
$$

With an increase in $\lambda$, resulting from lowering the pressure of the system, the average distance required for energy exchange between the high-temperature and lowertemperature regions increases. In a flat plate collector, when $\lambda$ is large, the hot collector plate and the gas molecules in contact or in the immediate neighborhood of the plate will have different temperature values. In this case, the temperature distribution is governed by the molecular activities.

Heat transfer by molecular flow is different from boundary layer (continuum flow) regime where the temperature of the hot plate and the gas in contact with it is assumed to have same temperature values. In the continuum regime, the pressure is near atmospheric and so the mean free path is very small. Hence, heat energy is more easily transferred by collision of molecules. The Nusselt number is usually used in correlating heat transfer in the boundary layer regime $[11,12]$.

A transition regime exits in which heat transfer is not exactly governed by molecular flow nor by continuum flow. This intermediate regime is further classified into slip and transition regimes $[13,14]$. Knudsen number $(\mathrm{Kn})$, a ratio of the mean free path of the gas molecules to the characteristic length $L$ of the device, describes the various regimes. $\mathrm{Kn}$ is calculated using (6) [15]. The characteristic length of the collector plate $L$ is defined here as the ratio of plate area to its perimeter. This and the average temperature $T_{\mathrm{e}}$ of the plate was used to verify the flow regimes and pressure ranges based on the Knudsen number. This is as shown in Table 1.

$$
\mathrm{Kn}=\frac{\lambda}{L}
$$

As the pressure is lowered, natural convection within the enclosure is also lowered. The main source of heat transfer therefore becomes conduction (by gas molecules) and radiation. At a sufficiently low pressure (the molecular flow regime), natural convection is completely eliminated. The thermal conductivity of gas varies with temperature and pressure. Kaminski [16] presented a correlation for the

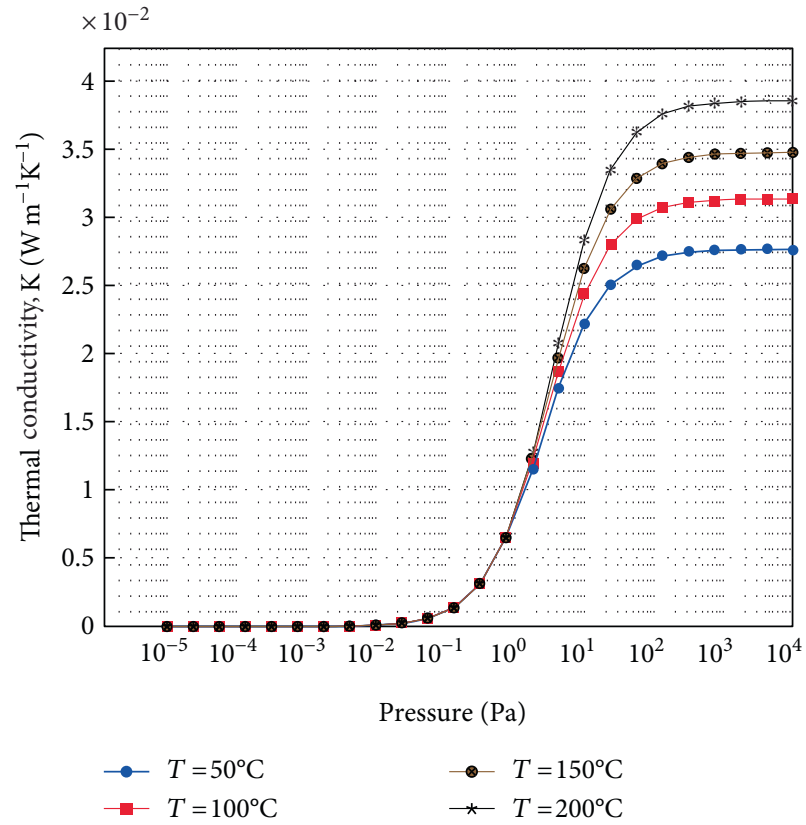

FIgURe 2: Pressure versus thermal conductivity of air at different temperatures.

pressure $(\mathrm{Pa})$ and temperature $(\mathrm{K})$ dependence of thermal conductivity as shown in

$$
k_{\mathrm{e}}=\frac{k_{\mathrm{o}}}{1+7.657 \times 10^{-5}(T / P d)},
$$

where $k_{\mathrm{o}}$ and $k_{\mathrm{e}}$ are the thermal conductivity of air at atmospheric and reduced pressure conditions, respectively. $d$ is the distance between the plates.

Overall, $k_{\mathrm{e}}$ decreases with decrease in pressure until the heat conduction is completely eliminated irrespective of operation temperature. The pressure dependence of air thermal conductivity is shown in Figure 2 for different temperatures.

2.1.2. Collector Plate Energy Balance. The useful energy harvested by a solar collector is determined by the ability of the surface to absorb incident radiation as well as the capacity of the body to limit long wavelength radiation from the surface. Further, the convection losses from the collector plate to the ambient air limit the overall useful energy gain. Equation (8) shows the available useful energy $\dot{Q}_{u}$ harvested by a solar thermal collector plate [17].

$$
\dot{Q}_{\mathrm{u}}=q_{\mathrm{u}} A_{\mathrm{c}}=(\tau \alpha) q_{\mathrm{s}} A_{\mathrm{c}}-\bar{U} A_{\mathrm{e}}\left(\overline{T_{\mathrm{e}}}-T_{\mathrm{a}}\right)-\epsilon \sigma A_{\mathrm{e}}\left(\bar{T}_{\mathrm{e}}^{4}-T_{\mathrm{a}}^{4}\right) .
$$

Equation (8) notes the overall balance as essentially: [useful energy harvested $]=$ [energy absorbed $]-[$ convection losses]-[radiation losses]. As can be noted, the energy absorbed depends on the transmissivity-absorptivity product $(\tau \alpha)$, the area of the collector $A_{c}$, and the incident solar radiation intensity $q_{\mathrm{s}}$. The radiation loss from the surface of the collector plate is directly proportional to the emissivity $\epsilon$ of 


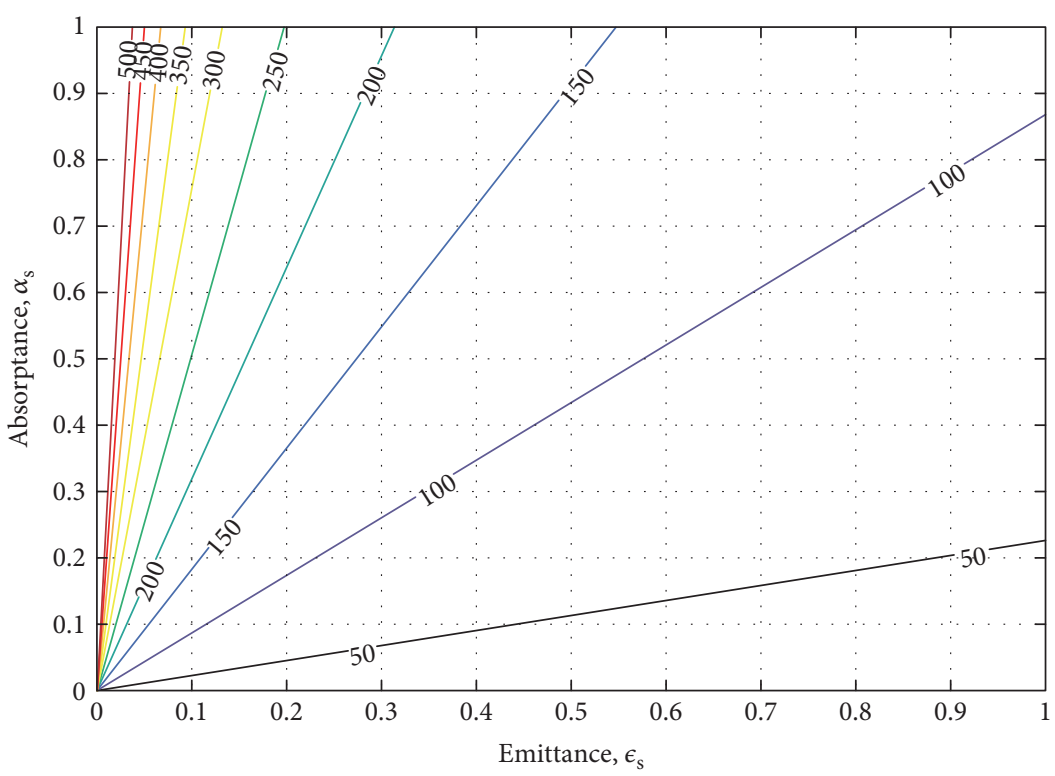

FiguRE 3: Steady-state temperature contour plot of a surface exposed to $750 \mathrm{~W} / \mathrm{m}^{2}$ and ambient temperature $T_{\alpha}$ of $25^{\circ} \mathrm{C}$ based on absorptivity and emissivity of the surface.

the surface. Further, since the sides of the collector as well as the top and bottom surfaces are subject to convection and conduction losses, the overall heat transfer coefficient $\bar{U}$ is critical in determining the amount of loss from the plate. These parameters are analyzed as part of this numerical effort as follows.

2.1.3. Steady-State Temperature. The temperature of the absorber element rises as radiation is absorbed. Hence, the temperature varies with time. However, to simplify this analysis, a steady-state (thermal equilibrium) condition is assumed. Hence, this section presents the steady-state temperature conditions for a solar collector element.

At thermal equilibrium, the energy absorbed by the collector is equal to that lost from the surface such that there is no net energy gain as shown in (9). If the cover glass is highly transmissive such that $\tau_{\mathrm{g}} \sim 1$, then the absorbed energy is dependent on the solar absorptivity $\alpha_{\mathrm{s}}$ of the surface while the amount of losses from the collector is related to the emittance $\epsilon$ and the heat loss coefficient $\bar{U}$ [17].

$$
\begin{aligned}
0 & =\alpha_{\mathrm{s}} q_{\mathrm{s}} A_{\mathrm{c}}-\bar{U} A_{\mathrm{e}}\left(\overline{T_{\mathrm{e}}}-T_{\mathrm{a}}\right)-\epsilon \sigma A_{\mathrm{e}}\left(\bar{T}_{\mathrm{e}}^{4}-T_{\mathrm{a}}^{4}\right), \\
\alpha_{\mathrm{s}} q_{\mathrm{s}} A_{\mathrm{c}} & =\bar{U} A_{\mathrm{e}}\left(\overline{T_{\mathrm{e}}}-T_{\mathrm{a}}\right)+\epsilon \sigma A_{\mathrm{e}}\left(\bar{T}_{\mathrm{e}}^{4}-T_{\mathrm{a}}^{4}\right) .
\end{aligned}
$$

The ability to achieve high temperature values is critical for a system that relies on thermal energy as input. The goal is, then, to design a system that maximizes temperature gain from the sun's heat energy. Typically, in a flat plate solar collector, there is no optical concentrating device. Hence, the area of the collector $A_{\mathrm{c}}$ is equal to the area of the absorber element of the collector $A_{\mathrm{e}}$. This reduces (10) to

$$
\alpha_{\mathrm{s}} q_{\mathrm{s}}=\bar{U}\left(\overline{T_{\mathrm{e}}}-T_{\mathrm{a}}\right)+\epsilon \sigma\left(\bar{T}_{\mathrm{e}}^{4}-T_{\mathrm{a}}^{4}\right) .
$$

2.1.4. Negligible Heat Loss Coefficient. If the collector's overall heat loss coefficient is negligible (i.e., $\bar{U}=0$ ) such that there are no convection or conduction losses from the plate, then the stagnation temperature of the collector (from 11) can be rewritten as (12). It has been demonstrated that vacuum packaging at a pressure of $10 \mathrm{mTorr}(\sim 1.3 \mathrm{~Pa})$ or below is sufficient to effectively eliminate conductive and convective heat losses [18]. It should be noted that in a real world setting with a structure formally attached around the collector (Figure 1), additional losses to those supporting structures and sidewalls will increase these losses.

$$
\overline{T_{\mathrm{e}}}=\sqrt[4]{T_{\mathrm{a}}^{4}+\left(\alpha_{\mathrm{s}} q_{\mathrm{s}} / \epsilon \sigma\right)} .
$$

Figure 3 shows the achievable temperatures under different $\alpha_{\mathrm{s}}$ and $\epsilon$ values. It can be seen that a flat plate collector will achieve a stagnation temperature above $300^{\circ} \mathrm{C}$ if the infrared emissivity is kept below 0.132 and there are no conduction and convection losses from the plate. Lower values of infrared emissivity will be required depending on the value of the collector absorptivity. A detailed review of absorber coating materials yielding varying absorptivity and emissivity values is given in [19]. Many of these coating materials are commercially available.

In this work, nickel-tin (Ni-Sn) coating has been selected as the collector absorber material. We have previously demonstrated this collector in small-scale application in ambient conditions [20]. This prior work has indicated that black Ni-Sn selective coating has promising potential as a highly effective selective absorber structure with absorptivity $\alpha_{\mathrm{s}}$ of 0.98 and emissivity $\epsilon$ of 0.10 [21].

2.1.5. Heat Loss Coefficient Effect. Despite the negligible thermal losses predicted at low pressures, in real world applications, the amount of heat absorbed by the collector is reduced by those losses from the collector. The effect of losses 
on the collector plate can be specifically studied through the use of established collector plate models for overall heat loss effects. Results of this study are shown in Figure 4, clearly demonstrating the relationship between heat loss and operating plate temperature. Experimental results correlate well (Section 3.2) and indicate that despite the low pressure conditions of the experimental setup, loss to the surroundings did occur. This was expected given the operating pressure that was above the threshold levels of $10 \mathrm{mTorr}(1.3 \mathrm{~Pa})$ [18].

If steady-state condition is assumed, the net useful heat gain absorbed by the collector is zero. Equation (11) is used to evaluate the effect of heat loss coefficient $\bar{U}$ on the steady-state temperature of the absorber element $T_{\mathrm{e}}$. This assumes known values of incident radiation, solar absorptivity $\alpha_{\mathrm{s}}$, emissivity $\epsilon$, and ambient temperature $T_{\mathrm{a}}$.

The overall heat loss coefficient, $\bar{U}$, is a function of various parameters. These include the temperature of the absorber plate, glass cover, and ambient temperature, emissivity of absorber $\left(\epsilon_{\mathrm{e}}\right)$ and glass cover $\left(\epsilon_{\mathrm{g}}\right)$, number of glass cover plates $(\mathrm{N})$, air gap distance, plate tilt angle, $\beta$ thermal conductivity of insulation material $(k)$ and its thickness $(x)$, and convective heat transfer coefficient $\left(h_{\mathrm{a}}\right) . \bar{U}$ from the absorber surface to the ambient is the sum of the top loss coefficient $\bar{U}_{\text {top }}$, edge loss coefficient $\bar{U}_{\text {edge, }}$, and the backloss coefficient $\bar{U}_{\text {back }}$, as shown in.

$$
\bar{U}=\bar{U}_{\text {top }}+\bar{U}_{\text {edge }}+\bar{U}_{\text {back }} .
$$

An equation for $\bar{U}_{\text {top }}$, developed by Klein [22] and modified by Duffie and Beckman [23], is presented in (equation 14). This is used to approximate the thermal loss coefficient to the ambient environment. The ambient wind loss coefficient $h_{\mathrm{a}}$ and the temperature gradient between the glass cover and the ambient influence the top loss heat transfer coefficient.

$$
\begin{aligned}
\bar{U}_{\text {top }}= & {\left[\frac{N}{C / T_{\mathrm{e}}\left[\left(T_{\mathrm{e}}-T_{\mathrm{a}}\right) /(N+f)\right]^{\mathrm{e}}}+\frac{1}{h_{\mathrm{a}}}\right]^{-1} } \\
& +\left[\frac{\sigma\left(T_{\mathrm{e}}+T_{\mathrm{a}}\right)\left(T_{\mathrm{e}}^{2}+T_{\mathrm{a}}^{2}\right)}{\left(\epsilon_{\mathrm{e}}+.00591 N h_{\mathrm{a}}\right)^{-1}+\left(2 N+f-1+.13 \epsilon_{\mathrm{e}} / \epsilon_{\mathrm{g}}\right)-N}\right],
\end{aligned}
$$

where

$$
\begin{aligned}
& C=520\left(1-.000051 \beta^{2}\right), \\
& f=\left(1+.089 h_{\mathrm{a}}-.1166 h_{\mathrm{a}} \epsilon_{\mathrm{e}}\right)(1+.07866 N), \\
& e=.43\left(1-\frac{100}{T_{\mathrm{e}}}\right) .
\end{aligned}
$$

Further, the back-loss and edge-loss coefficients can be solved using (16) and (17) [24].

$$
\bar{U}_{\text {back }}=\frac{k_{\mathrm{b}}}{x_{\mathrm{b}}},
$$

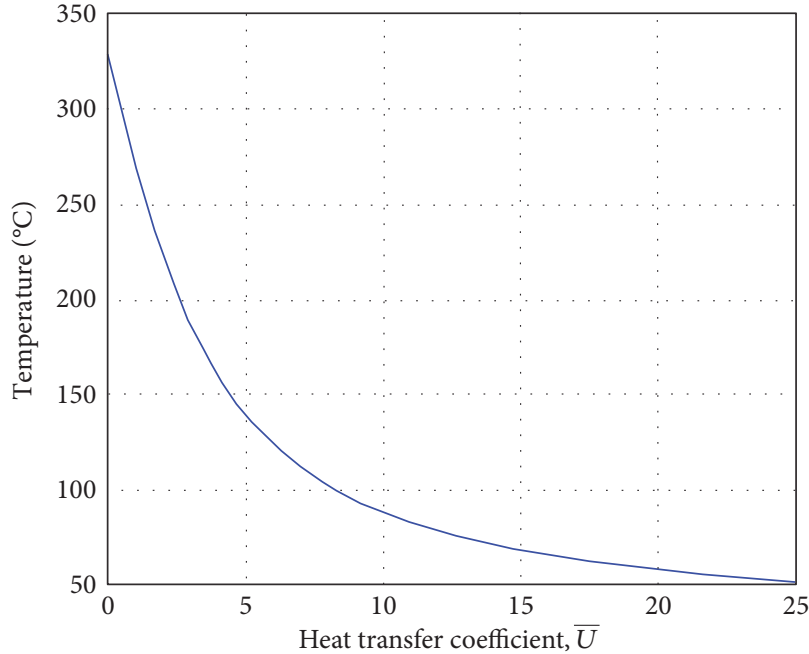

FIGURE 4: Effect of overall heat transfer coefficient $\bar{U}$ on the steadystate temperature of a surface exposed to $750 \mathrm{~W} / \mathrm{m}^{2}$ and ambient temperature $T_{\mathrm{a}}$ of $25^{\circ} \mathrm{C}$, based on absorptivity of 0.91 and emissivity of 0.1 .

$$
\bar{U}_{\text {edge }}=\frac{k_{\mathrm{e}}}{x_{\mathrm{e}}}\left[\frac{(L+W) H}{L W}\right] .
$$

$L \times W$ is the area of the absorber, and $\mathrm{H}$ is the height of the collector casing. Buchberg et al. [25] have suggested the following correlation (18) for solving the natural convection heat transfer coefficient in the enclosed space between the absorber plate and glass cover.

$$
h=\frac{\mathrm{Nu} \cdot k}{L},
$$

where $\mathrm{Nu}$ is the Nusselt number, $k$ is the thermal conductivity of air, and $L$ is the air gap. $\mathrm{Nu}$ may be calculated using [26].

$$
\begin{aligned}
\mathrm{Nu}= & 1+1.44\left[1-\frac{1708}{\cos \beta \cdot \mathrm{Ra}}\right]\left[1-\frac{\sin (1.8 \beta)^{1.6} \cdot 1708}{\cos \beta \cdot \mathrm{Ra}}\right] \\
& +\left[\left(\frac{\cos \beta \cdot \mathrm{Ra}}{5830}\right)^{1 / 3}-1\right] .
\end{aligned}
$$

$\mathrm{Ra}$ is the Rayleigh number (a product of the Grashof and Prandtl numbers) given by

$$
\mathrm{Ra}=\mathrm{Gr} \times \operatorname{Pr}=\frac{g \beta(\Delta T) d^{3}}{v^{2}} \times \operatorname{Pr} .
$$

2.2. Fabrication. The fabrication and testing of a solar selective absorber coating in atmospheric pressure conditions have been reported in prior published work. Fabrication of the collector plates that were tested as part of this effort is also reviewed and has been published in prior work [20]. A brief overview of the fabrication of these plates is included in this section.

Fabrication of the solar thermal collector plates began with selection of a copper plate to serve as the substrate. $200 \mu \mathrm{m}$ thick copper sheeting was selected for this work. To 


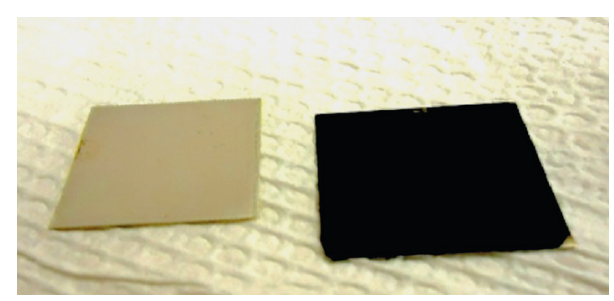

Figure 5: Copper solar collector plate with intermediate $10 \mathrm{pm} \mathrm{Ni}$ layer (left) and final nickel-tin selective coating (right).

this base, a "selective" absorber coating was applied. Selective coatings have been shown to effectively maximize absorption of incident solar radiation while limiting loss in the infrared region [23]. The coating was applied through an electrodeposition process in two steps. First, a nickel base undercoating layer was applied to a thickness of about $10 \mu \mathrm{m}$. To this intermediate layer, the final selective absorber coating was applied.

Thickness of the black selective absorber coating was applied based on literature indicating effective thicknesses in the range of 100 to $200 \mathrm{~nm}$ [27]. The coating was a bimetallic nickel-tin that was electrodeposited at room temperature in a neutral $\mathrm{pH}$ electroplating bath. Current densities and other specific electroplating bath parameters are included in the prior published efforts [21]. An example of the completed collector plate is shown in Figure 5, ready for use in these new low-vacuum condition tests.

2.3. Test Setup and Procedure. This section describes tests conducted to thermally characterize the performance of collector plates in low thermally conductive environments. Two tests were conducted. The first was conducted under atmospheric conditions similar to previously reported tests [20]. These formed the baseline data for this present work. The second test was conducted under an evacuated environmental condition. Lower pressure conditions as noted previously limit heat losses. Hence, the effect of pressure variation on temperature was experimentally studied using the fabricated small-scale STC. Both tests were conducted with the collector plate setup in an enclosed chamber. This further helped to limit and purposefully control convection losses from the ambient.

A halogen lamp was used to simulate solar radiation in this experiment. The simulator lamp used was a Sun System R SS-2 MH $400 \mathrm{~W}$ lamp. All tests were conducted by exposing the collector plate to incident radiation from the lamp. Like the sun, the intensity of the radiation from the lamp varied with distance. As the distance from the lamp increased, the intensity of output decreased. A Hukseflux SR11 pyranometer was used to validate the intensity of the radiation at various distances from the simulator lamp. This information was used to select an appropriate distance from the lamp which simulated flux density closely approximating real world availability. A $Z$-axis laboratory jack was used in adjusting the height of the test setup from the lamp.

An intensity of approximately $796 \mathrm{~W} / \mathrm{m}^{2}$ was selected. The pyranometer was used to determine the required

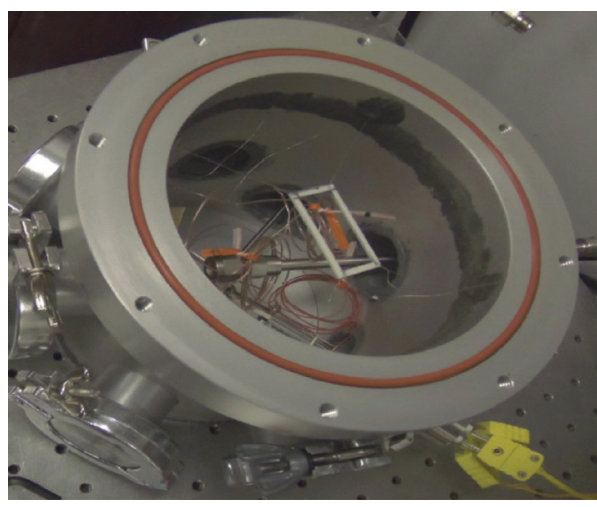

Figure 6: Vacuum chamber with suspended fiberglass frame for collector plate mounting.

distance from the simulator lamp. The experiment was placed in a vacuum chamber to minimize heat losses during experimentation. The vacuum chamber was cast and designed specifically for these tests of small-scale collectors. A highly transmissive glass window provided top cover to the chamber. The transmissivity of the chamber glass cover was verified by passing the simulated solar radiation through the lid and measuring its flux density via Pyranometer. The result showed that the glass had a transmissivity of 0.98 . This amounted to a radiation intensity of approximately $780 \mathrm{~W} / \mathrm{m}^{2}$ reaching sample surfaces inside the chamber. Other features of the chamber included different CF style bulkhead fittings that allowed pass-through of wires as needed to fully operate and characterize the collector plates in the altered environment.

A fiberglass material (Garolite G-7 from McMaster-Carr) was used as a frame to support the collector plate at the center of the chamber. The frame was suspended as shown in Figure 6 using 36 SWG (standard wire gauge) nichrome wires. Garolite G-7 was selected due to its very low thermal conductivity (on the order of $0.3 \mathrm{~W} / \mathrm{mK}$ ) and high mechanical strength. The low thermal conductivity further limited unintended thermal conduction from the collector during operation while the mechanical strength ensured stable support for the collector plate. The nichrome wires were epoxied to the chamber wall. This created a suspended base for the collectors. Each collector was placed on the fiberglass base such that the collectors did not extend to the nichrome wires. This way, heat loss through conduction from the collector plate was only via low conductive fiberglass.

The temperature of the collector plate and chamber environment when exposed to incident radiation were monitored using thermocouples (TCs) (SA1-k-120 from Omega Engineering). The first TC was placed on the back side of the collector plate. This monitored the plate temperature during operation. The second TC was suspended within the chamber to directly monitor the temperature within the chamber. A thermocouple feedthrough (TFT3KY00008B from Lesker, USA) was used to fit the TCs through the vacuum chamber wall. This was useful in maintaining the isolated environment. National Instruments LabVIEW (using a cDAQ-9174 data logger) was used to record all TC data to a computer 


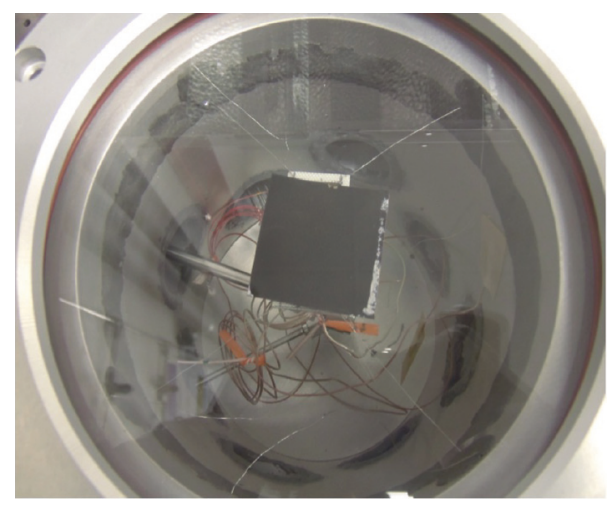

FIgURE 7: Top-down view of collector plate (STC) mounted in a vacuum chamber ready for testing.

for analysis. Figure 7 shows the vacuum chamber setup with mounted collector plate ready for testing.

With collector plate mounted within the vacuum chamber and TCs connected, a vacuum pump was connected with pressure sensor to vary the working condition of the collector environment. This readied the plates for testing.

\section{Results and Discussion}

3.1. Numerical Results. First, results from the numerical analysis are presented. Figure 4 shows the relationship between average heat loss coefficient, $\bar{U}$, and $T_{\mathrm{e}}$. Actual absorptivity $\alpha_{\mathrm{s}}$ determined from prior published work was used for this analysis [20]. Hence, this plot utilizes incident radiation of $750 \mathrm{~W} / \mathrm{m}^{2}$, absorptivity of 0.91 , and emissivity of 0.1 .

It can be seen from Figure 4 that as the heat loss coefficient increases, there is a significant decrease in the absorber plate temperature. Hence, adequate thermal insulation must be utilized to limit heat losses from the plate. Further, the overall heat loss coefficient and other parameters were estimated based on the formulations of Section 2.1. The range of variables as determined are listed in Table 2 . The values obtained were compared to results of experimental tests discussed in the next section. Of note were the predicted temperatures of the plate which were directly validated through the ensuing experimental effort.

3.2. Experimental Results. This section presents results of experimental tests conducted to validate the numerical analysis. Temperature of the collector plates was monitored when exposed to radiation flux as described in Section 2.3. Two tests were conducted. The first recorded the temperature of the plate under atmospheric conditions while the second test was conducted under an evacuated volume. In both cases, the temperature of the plates and the vacuum chamber were monitored until steady-state conditions were achieved.

Figure 8 shows the collector temperature plot for both atmospheric and partial vacuum test conditions. The temperature profile showed that the plate had a stagnation temperature of $96^{\circ} \mathrm{C}$ under atmospheric conditions. Following the atmospheric condition tests, the collector plate was also tested to characterize the effect of low pressure conditions on the thermal performance of the plate. The pressure of
TABLE 2: Small-scale solar collector specification variables.

\begin{tabular}{lc}
\hline Variable & Range \\
\hline Ambient temperature, $T_{\mathrm{a}}$ & $298 \mathrm{~K}$ \\
Absorber plate temperature, $T_{\mathrm{e}}$ & $363-388 \mathrm{~K}$ \\
Absorber plate emittance, $\epsilon_{\mathrm{e}}$ & 0.1 \\
Glass cover emittance, $\epsilon_{\mathrm{g}}$ & 0.90 \\
Collector tilt angle, $\beta$ & $0^{\circ}$ \\
Collector length, $L$ & $0.04 \mathrm{~m}$ \\
Collector width, $W$ & $0.04 \mathrm{~m}$ \\
Number of cover, $N$ & 1 \\
Insulation material & Vacuum \\
Wind heat transfer coefficient, $h_{\mathrm{a}}$ & $1-10 \mathrm{~W} / \mathrm{m}^{2} \mathrm{~K}$ \\
Top loss coefficient, $\bar{U}_{\text {top }}$ & $1.68-4.40 \mathrm{~W} / \mathrm{m}^{2} \mathrm{~K}$ \\
Total loss coefficient, $\bar{U}$ & $3.10-7.86 \mathrm{~W} / \mathrm{m}^{2} \mathrm{~K}$ \\
\hline
\end{tabular}

the chamber was lowered to $715 \mathrm{mTorr}$, or $95.3 \mathrm{~Pa}$, (from atmospheric) and held constant at this point throughout each test. The results showed an increased slope of the temperature profile. The stagnation temperature of the plate was $115^{\circ} \mathrm{C}$, representing an increase of about $16 \%$. The chamber interior temperature was also monitored in each test. In both cases, the chamber temperature stagnated at about $58^{\circ} \mathrm{C}$. This is much lower than the temperature of the plate for each test confirming that the plates were heated directly by thermal radiation and not by greenhouse effect within the chamber.

To further confirm that temperature gain recorded under partial vacuum conditions was primarily due to space evacuation, air molecules were reintroduced into the chamber after steady-state conditions were reached. The vacuum release points are as shown in Figure 8. As the chamber pressure increased, the temperature of the plate declined. As the chamber pressure increased back to atmospheric conditions, the temperature of the collector again matched the temperature obtained previously under atmospheric condition testing. Similar result was also noted for the chamber temperature. The reduction in collector temperature was caused by energy losses occasioned by the presence of air molecules within the chamber. These results agreed with numerical results which predicted an increase in collector temperature that closely agreed with experiment (Table 2). This allows the developed model to be used for design and prediction of different collector plates of different size and scale that will be well suited to a variety of applications or installations.

\section{Conclusions}

Small-scale energy scavenging through solar thermal application has great potential to provide power to a variety of sensors or other remote devices that may be fully autonomous in their operation. In this effort, a small-scale solar thermal collector (STC) is fabricated and tested in a simulated low vacuum environment. In parallel, a numerical model is developed that can be utilized to design and predict operation of STCs of varying sizes and operating environments. 


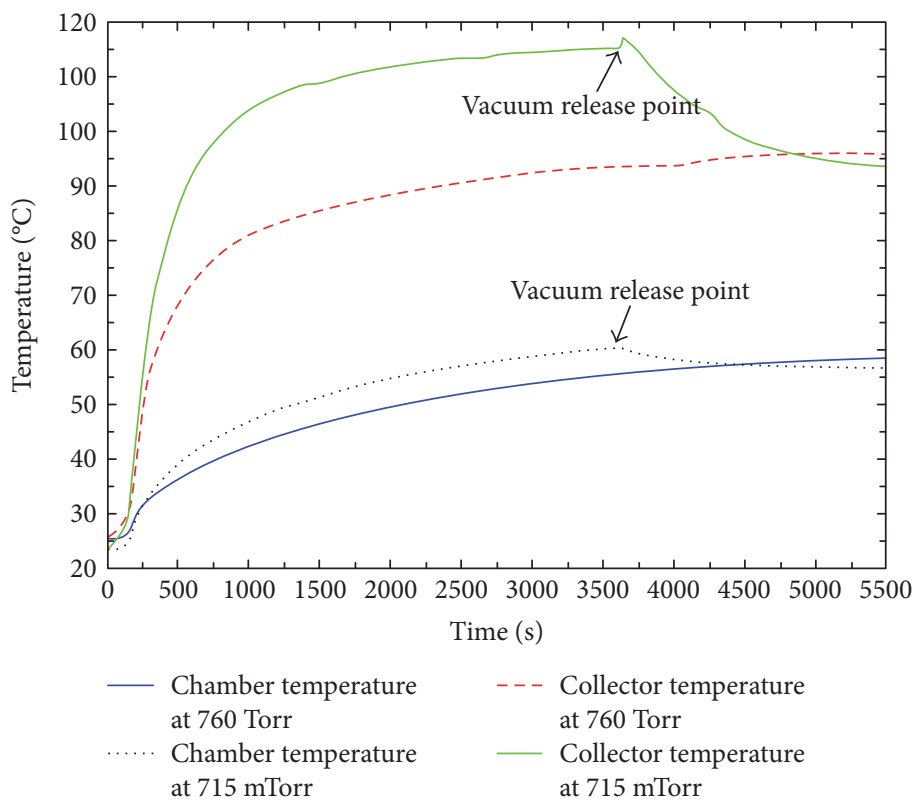

Figure 8: Collector plate operating temperature at different atmospheric pressures.

The STC itself was fabricated using a copper substrate and tin-nickel coating to form a selective surface. Tests were conducted to verify the operation temperature of collector plates when exposed to simulated solar radiation. Results showed an improvement in the stagnation temperature of the collector plate when operated in a partial vacuum environment $(715 \mathrm{mTorr}, 95.3 \mathrm{~Pa})$ compared to results obtained under atmospheric pressure. Total increase was about $16 \%$ for a collector plate with surface area of 40 by $40 \mathrm{~mm}$. The model proved a useful tool for future development efforts based on comparison to the experimental results.

Continuing and future work will examine the temperature of the plate under higher vacuum conditions. Effort is also underway to examine the effect of other operation environments with low thermal conductivity gases like argon, xenon and krypton. This way, rather than maintaining a vacuum environment, other gases (with thermal conductivity lower than air) may be utilized to replace air molecules within the operation environment.

\section{Conflicts of Interest}

The authors declare that they have no conflicts of interest.

\section{Acknowledgments}

The authors gratefully acknowledge the support of this work by the NSF via Grant no. ECCS- 1053729.

\section{References}

[1] M. Alghoul, M. Sulaiman, B. Azmi, and M. A. Wahab, "Review of materials for solar thermal collectors," Anti-Corrosion Methods and Materials, vol. 52, no. 4, pp. 199-206, 2005.
[2] A. M. Papadopoulos, "State of the art in thermal insulation materials and aims for future developments," Energy and Buildings, vol. 37, no. 1, pp. 77-86, 2005.

[3] B. P. Jelle, A. Gustavsen, and R. Baetens, "The high performance thermal building insulation materials and solutions of tomorrow," in Proceedings of the Thermal Performance of the Exterior Envelopes of Whole Buildings XI International Conference (Buildings XI), pp. 5-9, Clearwater Beach, Florida, USA, 2010.

[4] M. Reim, W. Korner, J. Manara et al., "Silica aerogel granulate material for thermal insulation and daylighting," Solar Energy, vol. 79, no. 2, pp. 131-139, 2005.

[5] A. Aergogels, "Spaceloft 3251, 6251, 9251: flexible insulation for industrial, commercial and residential applications," 2007, http://www.airtightdistribution.com/.

[6] A. Aergogels, Spaceloft 6250, Extreme Protection for Extreme Environments, 2007.

[7] R. Baetens, B. P. Jelle, J. V. Thue et al., "Vacuum insulation panels for building applications: a review and beyond," Energy and Buildings, vol. 42, no. 2, pp. 147-172, 2010.

[8] J. Vestlund, M. Ronnelid, and J.-O. Dalenback, "Thermal performance of gas-filled flat plate solar collectors," Solar Energy, vol. 83, no. 6, pp. 896-904, 2009.

[9] J. H. Lau, C. Lee, C. Premachandran, and A. Yu, Advanced MEMS Packaging, Citeseer, McGraw-Hill, New York, 2010.

[10] A. Chambers, R. K. Fitch, and B. S. Halliday, Basic Vacuum Technology, Institute of Physics Publishing, London, 1998.

[11] C. Y. Warner and V. S. Arpaci, "An experimental investigation of turbulent natural convection in air at low pressure along a vertical heated flat plate," International Journal of Heat and Mass Transfer, vol. 11, no. 3, pp. 397-406, 1968.

[12] S. W. Churchill and H. H. Chu, "Correlating equations for laminar and turbulent free convection from a vertical plate," International Journal of Heat and Mass Transfer, vol. 18, no. 11, pp. 1323-1329, 1975.

[13] X. Chen and E. Pfender, "Effect of the Knudsen number on heat transfer to a particle immersed into a thermal 
plasma," Plasma Chemistry and Plasma Processing, vol. 3, no. 1, pp. 97-113, 1983.

[14] S. Kakac, H. Liu, and A. Pramuanjaroenkij, Heat Exchangers: Selection, Rating, and Thermal Design, CRC press, New York, 2012.

[15] J. P. Holman, Heat Transfer, McGraw Hill, Inc, New York, 8th edition, 1997.

[16] D. A. Kaminski, Fluid Flow Data Book, General Electric Company, Boston, 1980.

[17] J. R. Howell, R. B. Bannerot, and G. C. Vliet, Solar-Thermal Energy Systems: Analysis and Design, Mcgraw-Hill College, New York, 1982.

[18] L. R. Arana, S. B. Schaevitz, A. J. Franz, M. A. Schmidt, and K. F. Jensen, "A microfabricated suspended-tube chemical reactor for thermally efficient fuel processing," Journal of Microelectromechanical Systems, vol. 12, no. 5, pp. 600612, 2003.

[19] C. E. Kennedy, Review of Mid- to High-Temperature Solar Selective Absorber Materials, vol. 1617, National Renewable Energy Laboratory Golden, Colo, USA, 2002.

[20] E. Ogbonnaya, A. Gunasekaran, and L. Weiss, "Micro solar energy harvesting using thin film selective absorber coating and thermoelectric generators," Microsystem Technologiess, vol. 19, no. 7, pp. 995-1004, 2013.

[21] R. Kirilov, P. Stefchev, Z. Alexieva, and H. Dikov, "A high effective selective absorbing coating for solar thermal collectors," Solid State Phenomena, vol. 159, pp. 97-100, 2010.

[22] S. Klein, "Calculation of flat-plate collector loss coefficients," Solar Energy, vol. 17, no. 1, pp. 79-80, 1975.

[23] J. A. Duffie and W. A. Beckman, Solar Engineering of Thermal Processes, Intersciences Publication, USA, 1991.

[24] K. Sukhatme and S. P. Sukhatme, Solar Energy: Principles of Thermal Collection and Storage, Tata McGraw-Hill Education, New York, 1996.

[25] H. Buchberg, I. Catton, and D. Edwards, "Natural convection in enclosed spaces: a review of application to solar energy collection," ASME Journal of Heat Transfer, vol. 98, no. 2, pp. 182-188, 1976.

[26] K. Hollands, T. Unny, G. Raithey, and L. Konicek, "Free convective heat transfer across inclined air layers," ASME Journal of Heat Transfer, vol. 98, no. 2, 1976.

[27] N. Shanmugam, M. Selvam, K. Srinivasan, S. John, and B. Shenoi, "Black nickel-tin selective coatings for solar thermal energy conversion," Metal Finishing, vol. 82, no. 10, pp. 9195, 1984. 

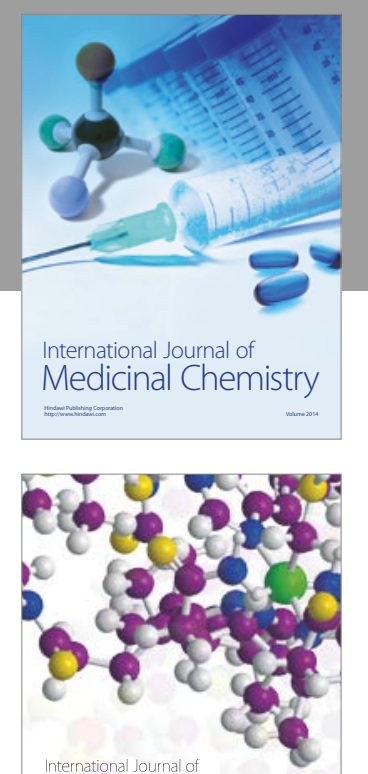

Carbohydrate Chemistry

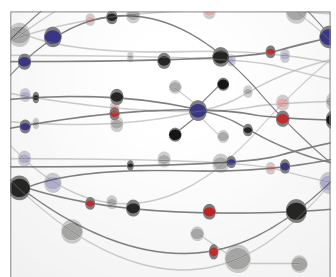

The Scientific World Journal
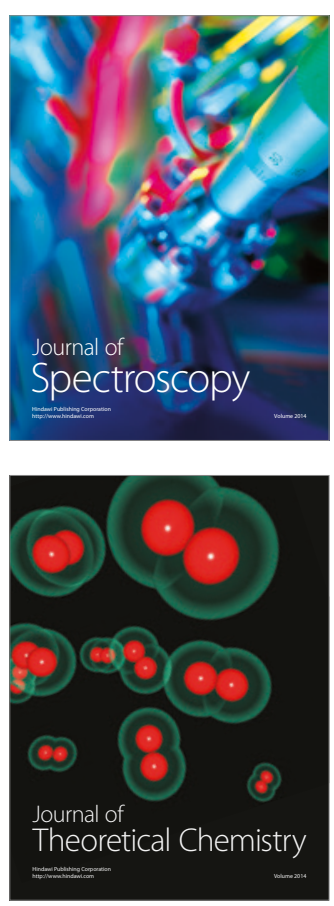
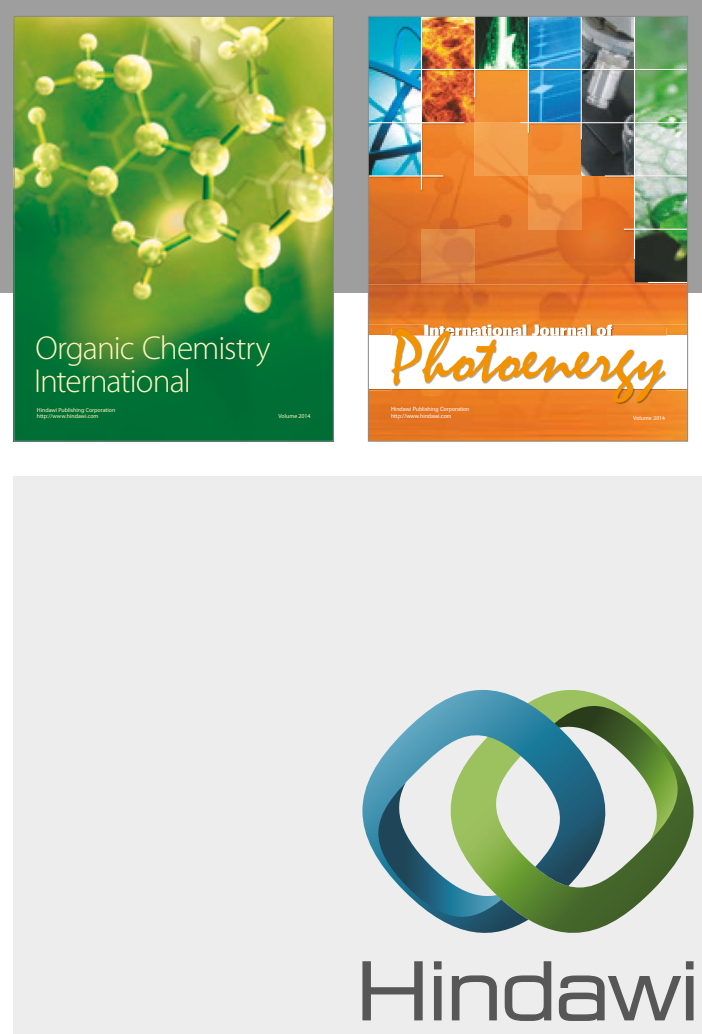

Submit your manuscripts at

https://www.hindawi.com

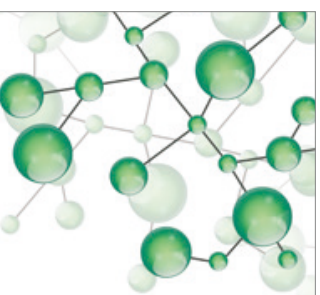

International Journal of

Inorganic Chemistry

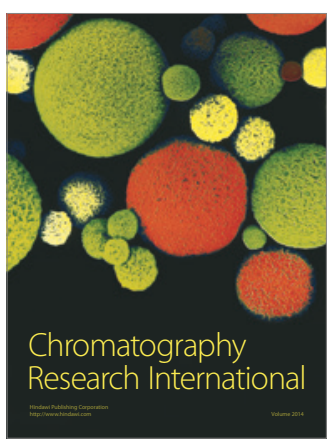

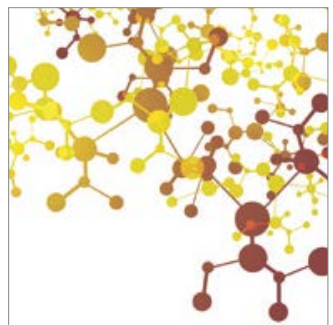

Applied Chemistry
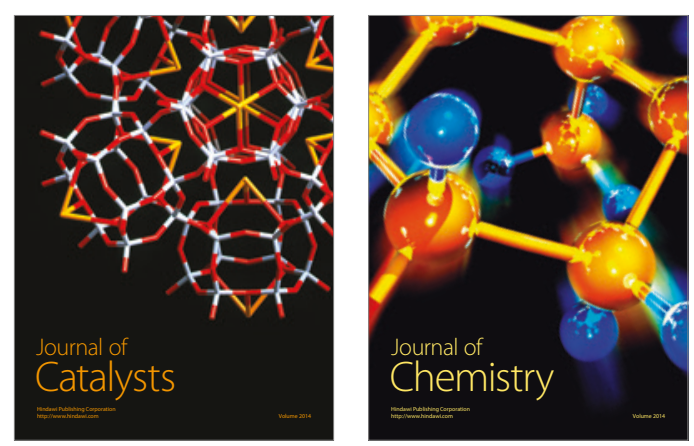
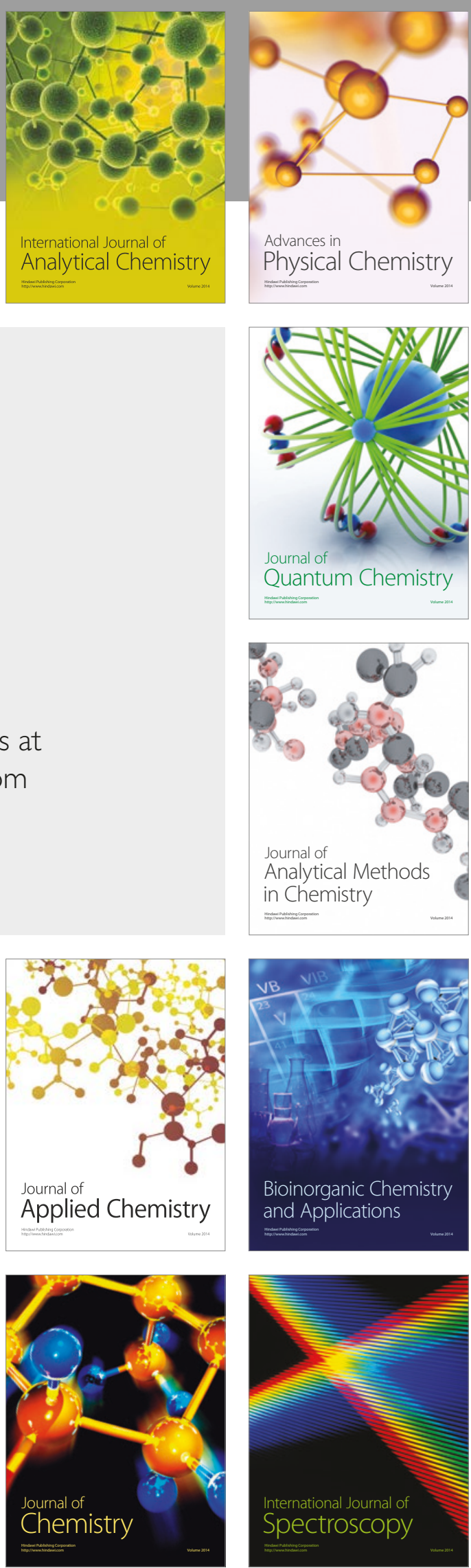